$$
\in \cup I C \mid \begin{aligned}
& \text { European Journal of } \\
& \text { Health Communication }
\end{aligned}
$$

ISSN 2673-5903

ejhc.org

Editorial

\title{
A European Journal of Health Communication in the Age of Open Science
}

DOI: $10.47368 /$ ejhc.2020.001

2020, Vol. 1(1) 1-6

CC BY 4.0

\section{Thomas N. Friemel (iD), Sarah Geber (iD, Nico Pfiffner}

Department of Communication and Media Research, University of Zurich, Switzerland

\section{Julia van Weert (iD, Gert-Jan de Bruijn}

Amsterdam School of Communication Research, University of Amsterdam, Netherlands

\section{Doreen Reifegerste (iD)}

Department for Media and Communication Studies, University of Erfurt, Germany

A decade ago, health communication research in Europe was still considered an emerging field (Schulz \& Hartung, 2010). Today, in response to the assiduous efforts of European researchers and scholars, we are proud to present the European Journal of Health Communication (EJHC). As the first journal that is explicitly dedicated to European health communication research, EJHC can be regarded as a further milestone in the establishment of our discipline in Europe. EJHC is based on the principles of open science by making publications openly available without imposing any charges on readers or authors and providing alternatives to the traditional review and publication process. With this editorial, we want to introduce EJHC as a European journal, emphasise the arguments for the set-up of EJHC as a platinum open access journal, illustrate our efforts to improve academic publishing with various innovations, and present the people behind EJHC.

\section{EJHC is a European Journal}

The growing societal relevance of health is linked to an increasing academic effort to understand the challenges and opportunities of communication theories and approaches to improve health determinants and outcomes. The establishment of the field of health communication research in 
Europe is evidenced by the foundation of the Health Communication Temporary Working Group of the European Communication Research and Education Association (ECREA) in 2017, as well as the increasing creation of specialised health communication departments and dedicated study programmes at various European universities. However, notably, this development is thus far not reflected in the publications of current journals on health communication. The origins of the authors who publish in the two major journals of the field, Health Communication and Journal of Health Communication, illustrate that European research still plays a marginal role.

Figure 1. Regional affiliations of the first authors of the articles published in Health Communication and Journal of Health Communication from 2010 to 2019

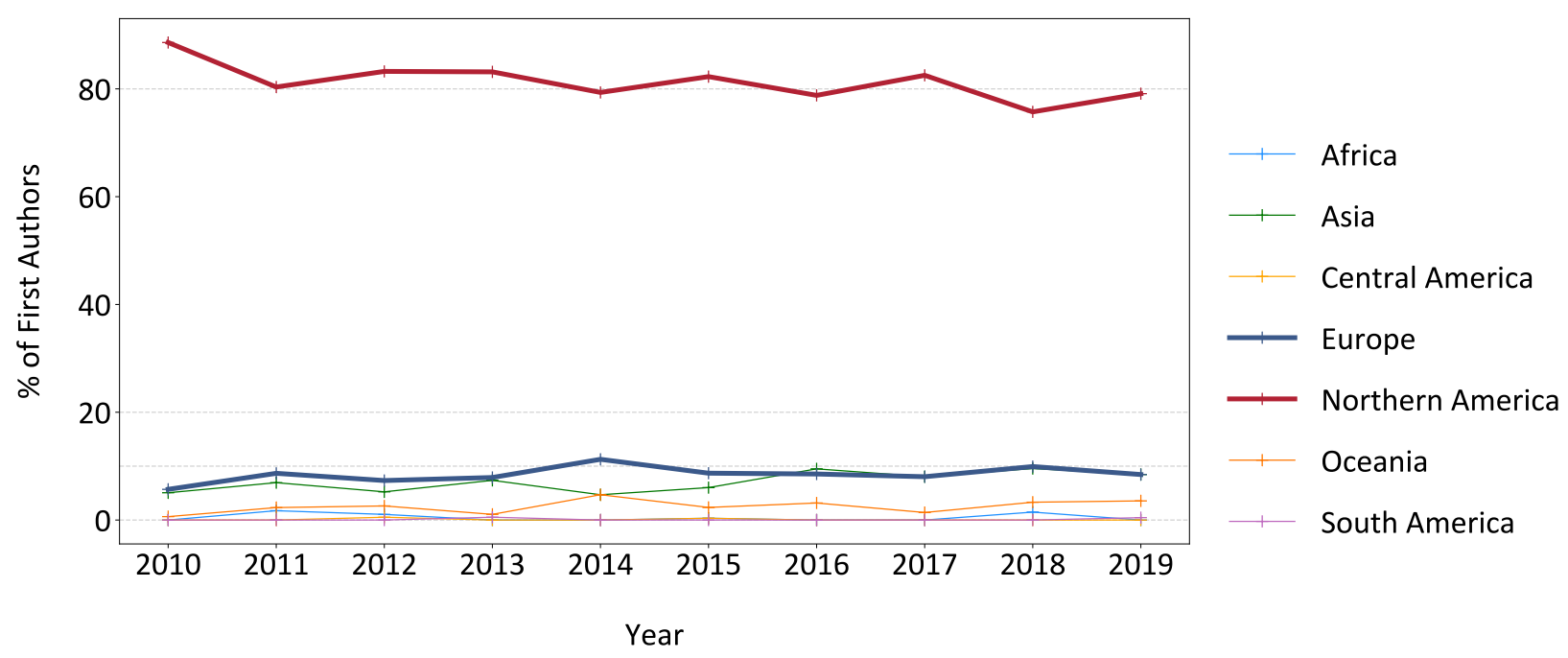

Note. The graph is based on data gathered from Crossref and publicly available information on the websites of the two journals. Only article-type publications are considered (e.g., no editorials, commentaries, etc.). All articles published in volumes 15 to 24 of the Journal of Health Communication and 25 to 34 of Health Communication are included $(n=2,332)$. The regional affiliation is derived from the geographical location of the institution to which the first author of an article belongs according to the information provided in the respective article.

Figure 1 demonstrates that over the last ten years, less than $10 \%$ of publications in both major journals were first-authored by Europe-based researchers. In comparison, the publications of USbased authors make up a share of more than $80 \%$ on average across this period. However, at the same time, numbers provided by Health Communication on downloads of their published articles (King, 2020) show that Europe accounted for more than one quarter (26\%) of downloads (United States and Canada 46\%), demonstrating a far more active field of health communication research in Europe than suggested by the publication share. The disproportional numbers can be regarded as an indicator for the historic development of the European community. The diversity of European languages and academic cultures resulted in a rich but loosely connected set of communities that were interested in learning from the international discourse but published their research in their respective languages. EJHC provides a platform to overcome these barriers and to intensify the discourse among European researchers and regarding topics that are of special relevance to Europe in general, to specific European countries, or to comparisons between Europe and other regions. 
Rooted in the European community of health communication researchers, EJHC supports the institutionalisation of the field across the continent and represents the international character of health communication research given the cultural, political, economic, and academic diversity in Europe. Of course, academics from outside Europe are more than welcome to participate in this discourse and contribute to a better understanding of health-related challenges and potential coping strategies.

\section{EJHC is an Open Access Journal}

Following the principles of open science, EJHC is a platinum open access journal. As such, it makes publications openly available while charging neither the readers nor the authors. Academic research is publicly funded, and both academic editors and reviewers work voluntarily. The article processing charges (APC) that are imposed by the established international publishers are much higher than their actual costs and result in 'profit margins around 37\%, larger than Apple and big oil companies' (Tennant, 2018). Given this high profitability, an increasing number of companies are entering the field and founding journals with APC. With their focus on economic profitability, these predatory journals refrain from the necessary review process, provide misleading information regarding their institutional background, and thereby undermine the credibility of academic research and publication (Grudniewicz et al., 2019). We believe that the public funding of research and the voluntary work of editors and reviewers should be accessible free of charge and should not result in the financial profit of private companies. Thanks to open source software such as the Open Journal System (OJS), costs for electronic publishing have decreased to a minimum, and many associations and universities increasingly provide support for new publishing forms (Public Knowledge Project, 2020). Nevertheless, there are some costs remaining, and we are very grateful to the universities, departments, and academic associations that support EJHC to cover these costs (see below). Further sponsors are more than welcome to support this transformation of academic publishing and are invited to contact the management team.

\section{EJHC is an Innovative Journal}

EJHC combines established standards of quality assurance with innovative approaches to cope with the challenges and shortcomings of the traditional publication process, such as long publication cycles and publication biases. Like most journals in communication research, all articles submitted to EJHC undergo a rigorous double-blind peer review process. To ensure a timely review and publication process, EJHC builds on a broad editorial structure (see below) and an 'online-only strategy'. This means that articles are published immediately in their final form after acceptance. Since EJHC is an online-only journal, there is no need for online preprints without volume, issue, or page numbers. All articles are published with a digital object identifier (DOI) number and page numbers, enabling other researchers to refer to the content. Furthermore, we encourage authors to publish additional materials in order to support transparency and reproducibility. 
In addition to the traditional review process and as a procedural innovation, EJHC provides the opportunity to 'pre-register' original research before data collection. For this purpose, authors are invited to submit a proposal for a scientific question, presenting the theoretical background, hypotheses, and a detailed methods and analysis plan. The proposal will be reviewed, and if it is evaluated positively, the study will receive an 'in principle' acceptance. After completion of the study, authors submit the second part of their work presenting and discussing their results. Though the second part will undergo a review round (to evaluate whether the results and discussion sections meet the standards of the journal), the manuscript will be published regardless of whether the hypotheses are supported. We see pre-registration as a useful tool to avoid bias against null findings and to value such findings as a contribution to knowledge.

\section{EJHC is a Community Effort}

EJHC was officially announced on November 14, 2019, at the European Conference on Health Communication in Zurich. It was during the organisation of this conference that the pressing need for an outlet for the developing and growing European health communication community became apparent. As part of the organising team, Thomas Friemel and Sarah Geber reached out to Doreen Reifegerste and Julia van Weert as the co-chairs of the Thematic Working Group on Health Communication of ECREA to set up the first management team. This management team includes Thomas Friemel (University of Zurich), Doreen Reifegerste (University of Erfurt), and Julia van Weert (University of Amsterdam) as editors-in-chief, Sarah Geber (University of Zurich) and GertJan de Bruijn (University of Amsterdam) as managing editors, and Nico Pfiffner (University of Zurich) as editorial assistant.

Beside the management team, EJHC builds on a broad editorial structure encompassing the associate editors and the editorial board. The associate editors play a crucial role in covering the academic and cultural diversity of health communication in Europe. They are leading academics from different European countries and cover with their expertise the whole range of subdisciplines and issues. Namely and in alphabetical order, they are: Eva Baumann (Hanover University of Music, Drama and Media), Kathleen Beullens (KU Leuven), Anne-Linda Camerini (Università della Svizzera italiana), Gregor Petrič (University of Ljubljana), Constanze Rossmann (University of Erfurt), Barbara Schouten (University of Amsterdam), and Tom van de Belt (Radboud University). In addition, Petya Eckler (University of Strathclyde) supports EJHC as a language editor. The high personal commitment of these people ensures a qualified, fair, and timely review process that adheres to the highest academic standards. Furthermore, EJHC can count on 30 editorial board members who provide their services to the journal as reviewers in their areas of expertise. As of today, our editorial board includes, in alphabetical order, the following colleagues:

Florian Arendt, University of Vienna, Austria

Sara Atanasova, University of Ljubljana, Slovenia

Cabral A. Bigman, University of Illinois at Urbana-Champaign, USA

Nadine Bol, Tilburg University, Netherlands

Nicky Britten, University of Exeter, United Kingdom

Viorela Dan, LMU Munich, Germany 
Lidia del Piccolo, University of Verona, Italy

Andreas Fahr, University of Fribourg, Switzerland

Matthias Hastall, TU Dortmund, Germany

Hanneke Hendriks, University of Amsterdam, Netherlands

Tanja Kamin, University of Ljubljana, Slovenia

Veronika Karnowski, LMU Munich, Germany

Laura König, University of Konstanz, Germany

Demi Krystallidou, KU Leuven, Belgium

Nanon Labrie, VU Amsterdam, Netherlands

Claudia Lampert, Hans-Bredow-Institute, Hamburg, Germany

Yvan Leanza, Université Laval, Canada

Nehama Lewis, University of Haifa, Israel

Elena Link, Hanover University of Music, Drama and Media, Germany

Jennifer Manganello, University at Albany, USA

Saar Mollen, University of Amsterdam, Netherlands

Hao Nguyen, University of Zurich, Switzerland

Serena Petrocchi, Università della Svizzera italiana, Switzerland

Stephen A. Rains, University of Arizona, USA

Sara Rubinelli, University of Lucerne, Switzerland

Markus Schäfer, Johannes Gutenberg University Mainz, Germany

Sebastian Scherr, Texas A\&M University, USA

Eline Smit, University of Amsterdam, Netherlands

Rachel Smith, Pennsylvania State University, USA

Freya Sukalla, Leipzig University, Germany

As recently noted by Teresa L. Thompson, editor of Health Communication, the management of a journal is a 'community effort' (Thompson, 2020); this particularly applies to the founding phase of a journal. We, the management team, are all the more grateful for the support and positive feedback we have received since the founding of the journal. We want to particularly thank the main library of the University of Zurich that hosts and maintains the publishing platform. The team of the library provided great support in developing the editorial infrastructure for EJHC.

As a platinum open access journal that is free of charge for readers and authors, EJHC relies on sponsors. We are thankful for the financial support of the Department of Communication and Media Research (IKMZ), the Amsterdam School of Communication Research (ASCoR), and the Swiss Academy of Humanities and Social Sciences (SAGW).

Last but not least, we want to thank the community for its commitment to EJHC. This has been impressively demonstrated in the form of high-quality submissions; qualified, detailed, and timely reviews; and dedicated service to the journal in various forms. With this strong support, we are looking forward to jointly developing EJHC and the European field of health communication research in the coming years. In addition to the continuous publication of articles, this will be conducted through special issues, such as one on the 'social aspects of health communication', which will be published in the coming months. 


\section{References}

Grudniewicz, A., Moher, D., Cobey, K. D., Bryson, G. L., Cukier, S., Allen, K., Ardern, C., Balcom, L., Barros, T., Berger, M., Ciro, J. B., Cugusi, L., Donaldson, M. R., Egger, M., Graham, I. D., Hodgkinson, M., Khan, K. M., Mabizela, M., Manca, A., . . . Lalu, M. M. (2019). Predatory journals: No definition, no defence. Nature, 576(7786), 210-212. https://doi.org/10.1038/d41586-019-03759-y

King, A. J. (2020). Health Communication 2019 in review. Health Communication, 35(9), 10511055. https://doi.org/10.1080/10410236.2020.1763045

Public Knowledge Project. (2020). Open Journal Systems (OJS). https:/pkp.sfu.ca/ojs/

Schulz, P. J., \& Hartung, U. (2010). Health communication research in Europe: An emerging field. Health Communication, 25(6-7), 548-551. https://doi.org/10.1080/10410236.2010.496720

Tennant, J. (2018, June 29). Elsevier are corrupting open science in Europe. The Guardian. https://www.theguardian.com/science/political-science/2018/jun/29/elsevier-are-corruptingopen-science-in-europe

Thompson, T. L. (2020). Health communication as a community effort. Health Communication, 35(9), 1061-1062. https://doi.org/10.1080/10410236.2020.1763043 